\title{
Asesmen Bangunan Gedung Pemda Kota Palu, Donggala dan Parigi Moutong Pasca Gempa 28 September 2018
}

\author{
H. Listiawaty ${ }^{a}$, I.K. Sulendra ${ }^{a}$ dan T. Hilmansyah ${ }^{a}$ \\ a Jurusan Teknik Sipil, Fakultas Teknik Universitas Tadulako, Palu, Indonesia, 94112 \\ ${ }^{*}$ Corresponding author's e-mail: hlistiawaty@yahoo.com
}

Received: 04 February 2022; revised: 17 February 2022; accepted: 23 February 2022

\begin{abstract}
After a strong earthquake with a magnitude of 7.4 on the Richter Scale with a hypocenter of $10 \mathrm{~km}$ and an epicenter of about 70 $\mathrm{km}$ north of Palu City, precisely in Lende Village, Sirenja District, Donggala Regency, it caused damage and collapse of buildings due to vibrations, fractures of down lifts and up lifts around the fault trajectory. Palu-Koro. Damage and failure of high-rise and non-rise buildings occurred in Palu City, Donggala City, and Parigi City. Damage to the building can be categorized as light, moderate or heavy damage, so it is deemed necessary to conduct an assessment according to the applicable requirements both on a national scale (using the Ministry of Public Works and Public Housing's 2010 form) and an international form (using a form from the World Bank). This activity aims to determine the level of damage and post-earthquake handling in the form of minor repairs, reinforcement and repair of structural and nonstructural elements. There are 6 (six) main buildings in the 3 (three) areas that have been assessed to determine the category of damage and actions for rehabilitation and reconstruction. Damage to the building structure with the category of Light Damage occurred in the Palu City DPRD Office building, the Donggala Regent and DPRD Office and the Anuntaloko Parigi Hospital Inpatient Building. Those that were moderately damaged were the Palu Mayor's Office building and the Parigi Moutong DPRD office. The damaged buildings still allow for repairs and reinforcement according to the level of damage. The repair and strengthening of buildings in order to get good results must be carried out with the right method, good materials and tools and technology and carried out by experienced workers with high qualifications
\end{abstract}

Keywords: assessment, building structure, damage categories, rehabilitation, reconstruction

Abstrak: Pasca gempa kuat dengan magnitudo 7,4 SR dengan hiposenter $10 \mathrm{~km}$ dan episenter sekitar $70 \mathrm{~km}$ arah Utara Kota Palu tepatnya di Desa Lende Kecamatan Sirenja Kabupaten Donggala telah menyebabkan kerusakan dan keruntuhan gedung akibat getaran, rekahan down lift dan up lift yang di sekitar lintasan sesar Palu-Koro. Kerusakan dan kegagalan struktur gedung bertingkat maupun bangunan tidak bertingkat terjadi di Kota Palu, Kota Donggala, dan Kota Parigi. Kerusakan pada bangunan tersebut dapat dikategorikan sebagai kategori rusak ringan, sedang maupun berat, sehingga dirasa perlu untuk melakukan asesmen sesuai persyaratan yang berlaku baik skala nasional (menggunakan form Kementerian PUPR tahun 2010) maupun form yang bersifat internasional (menggunakan form dari World Bank). Kegiatan ini bertujuan untuk mengetahui tingkat kerusakan serta penanganan pasca gempa baik berupa perbaikan ringan, perkuatan dan perbaikan elemen struktur dan non strukturnya. Terdapat 6 (enam) bangunan utama di ke 3 (tiga) wilayah tersebut yang telah dilakukan asesmen untuk mengetahui kategori kerusakan dan tindakan untuk rehab dan rekonnya. Kerusakan struktur gedung dengan kategori Rusak Ringan terjadi pada bangunan Kantor DPRD Kota Palu, Kantor Bupati dan DPRD Donggala dan Gedung Rawat Inap RSUD Anuntaloko Parigi. Yang mengalami Rusak Sedang adalah gedung Kantor Wali Kota Palu dan kantor DPRD Parigi Moutong. Bangunan yang mengalami kerusakan tersebut masih memungkinkan dilakukan perbaikan dan perkuatan sesuai tingkat kerusakannya. Adapun perbaikan dan perkuatan bangunan agar mendapatkan hasil yang baik harus dilakukan dengan metode yang tepat, bahan dan alat serta teknologi yang baik serta dikerjakan oleh pekerja yang berpengalaman dengan berkualifikasi yang tinggi

Kata kunci: asesmen, bangunan gedung, kategori kerusakan, rehabilitasi, rekonstruksi

\section{Pendahuluan}

Fenomena gempa bumi, khususnya gempa tektonik selain merupakan suatu peristiwa yang menimbulkan ketakutan dan trauma sesungguhnya merupakan peristiwa yang dapat diambil pembelajarannya [1-4]. Dengan terjadinya peristiwa gempa, masyarakat yang wilayahnya berisiko tinggi mengalami peristiwa gempa harus kooperatif dan familiar terhadap bangunan sederhana tahan gempa [58].

Pada tahun 2010 Indonesia telah memperkenalkan peta zonasi gempa yang baru, peta ini terus mengalami pemutahiran karena magnitudo dan intensitas gempa yang terus meningkat [9-11]. Telah diketahui sekitar 295 sesar di wilayah Indonesia berdasarkan Peta Gempa Indonesia tahun 2017. Peta ini nantinya akan dimasukkan pada peraturan perencanaan bangunan tahan gempa yang baru menggantikan peraturan perencanaan bangunan tahan gempa yang lama (SNI-1726, tahun 2002 menjadi tahun 2018). Secara umum peta zonasi gempa yang baru ini cenderung akan memberikan beban gempa yang lebih besar pada bangunan dibandingkan dengan yang ditentukan dalam peraturan gempa yang lama tersebut [12]. Terkhusus wilayah Palu dan sekitarnya yang dilintasi sesar Palu-Koro yang catatan kegempaannya terus meningkat. Hal ini menjadi "warning" bagi semua stakeholder di wilayah ini untuk secara berkelanjutan melakukan proses mitigasi bencana gempa bumi [13].

Pasca Gempa Padagimo (Palu, Donggala, Sigi dan Parigi Moutong) pada 28 September 2018 masih menyisakan permasalahan yaitu masih ada bangunan yang belum dilakukan asesmen kondisi kerusakan pasca gempa 
serta upaya untuk rehab rekon. Permasalahan ini terkendala karena kekurangan tenaga teknis yang berkompoten di bidangnya serta masalah pembiayaan yang turun. Hal ini juga terjadi untuk bangunan Pemda di Kota Palu, Kota Parigi dan Perkantoran Pemda Donggala [14].

\section{Metode Penelitian}

\subsection{Lokasi Penelitian}

Penelitian ini berlokasi di tiga tempat yaitu Kota Palu (Kantor Walikota Palu dan Kantor DPRD Kota Palu), Kabupaten Donggala (Kantor Bupati dan Kantor DPRD Kab. Donggala) dan Kabupaten Parigi Moutong (Kantor DPRD Kab. Parigi Moutong dan Gedung Rawat Inap RSUD. Anuntaloko Parigi)

\subsection{Data}

Bahan penelitian yang digunakan dalam penelitian ini antara lain gambar konstruksi bangunan eksisting, data hasil uji tanah, data peta Kawasan rawan bencana Sulawesi Tengah, dan data pendukung termasuk hasil penilaian dari Dinas Pekerjaan Umum dan Perumahan Rakyat (PUPR).

Berdasarkan beberapa penelitian telah ditetapkan kategori kerusakan bangunan gedung berikut ciri-cirinya serta penanganan kerusakannya seperti pada Tabel 1 .

Tabel 1. Kategori kerusakan elemen struktur bangunan gedung.

\begin{tabular}{|c|c|c|c|}
\hline No & Tingkatan & $\begin{array}{l}\text { Kerusakan } \\
\text { Yang Tampak }\end{array}$ & $\begin{array}{l}\text { Tindakan Yang } \\
\text { Dianjurkan }\end{array}$ \\
\hline 1 & $\begin{array}{l}\text { Sangat } \\
\text { ringan }\end{array}$ & $\begin{array}{l}\text { Sejumlah retak } \\
\text { lentur dan retak } \\
\text { geser }\end{array}$ & $\begin{array}{l}\text { Perbaikan luar, } \\
\text { tidak ada } \\
\text { perbaikan } \\
\text { struktur }\end{array}$ \\
\hline 2 & Ringan & $\begin{array}{l}\text { Retak kecil } \\
\text { menyebar, } \\
\text { Lebar retak }<1 \\
\text { mm }\end{array}$ & $\begin{array}{l}\text { Perbaikan ringan } \\
\text { untuk } \\
\text { memulihkan } \\
\text { struktur pada } \\
\text { kuat desainnya }\end{array}$ \\
\hline 3 & Sedang & $\begin{array}{l}\text { Retak lentur } \geq \\
2 \mathrm{~mm} \\
\text { Retak geser } \geq 1 \\
\mathrm{~mm}\end{array}$ & $\begin{array}{l}\text { Struktur } \\
\text { diperbaiki untuk } \\
\text { beberapa minggu }\end{array}$ \\
\hline 4 & Berat & $\begin{array}{l}\text { Retak lentur } \\
\text { dan retak geser, } \\
\text { Spalling } \\
\text { selimut beton }\end{array}$ & $\begin{array}{l}\text { Struktur } \\
\text { diperbaiki } \\
\text { sebagian, dan } \\
\text { sebagian } \\
\text { dibongkar }\end{array}$ \\
\hline 5 & Runtuh & $\begin{array}{l}\text { Banyak retak } \\
\text { besar, } \\
\text { terkelupas, } \\
\text { tekuk tulangan }\end{array}$ & $\begin{array}{l}\text { Struktur } \\
\text { dibongkar total }\end{array}$ \\
\hline
\end{tabular}

\subsection{Metode dan Tahapan Penelitian}

Beberapa stakeholder yang telah melakukan penilaian (assessment) adalah :

1) Kementerian Pekerjaan Umum dan Perumahan Rakyat (KemenPUPR) tahun 2010
Penilaian dari Kementerian Pekerjaan Umum dan Perumahan Rakyat (KemenPUPR) didasarkan pada 3 (tiga) kategori kerusakan yaitu Rusak Ringan (RR) jika persentase kerusakan $<$ dari 30\%, Rusak Sedang (RS) jika persentase kerusakan antara 30\% - 50\% dan kategori Rusak Berat (RB) jika persentase kerusakan > $50 \%$. Selain persentase kerusakan, kemiringan dinding juga menjadi indikator. Jika kemiringan $>1 \%$ sudah dikategorikan Rusak Berat (RB) [15-17]. Retaknya sebagian besar dinding jika $>6 \mathrm{~mm}$ juga masuk kategori RS dan RB. Format asesmen ini berdasarkan pengembangan dari Permen 16/PRT/M/2010 yang membedakan tingkat kerusakan menjadi : Rusak Ringan, Sedang dan Berat (Tabel 4).

2) Bank Dunia (The Word Bank)

Penilaian dari Bank Dunia (The Word Bank) dalam formatnya menentukan kategori kerusakan pada lebar retakan dinding dan struktur utama (kolom, slof dan balok atap), jika lebar retakan $>5 \mathrm{~mm}$ sudah dikategorikan RS dan RB. Selain retakan dinding dan struktur utama, kerusakan lantai dan atap yang $>10 \%$ juga dikategorikan sebagai RS dan RB [18-19].

Formulir penilaian ini dimaksudkan untuk menilai keamanan bangunan secara keseluruhan, bukan hanya keamanan struktural (kekakuan kemiringan, beban, korosi tulangan, elemen kontrol gaya dan deformasi, tumbukan antar bangunan, kemiringan bangunan, efek partisi dan kerusakan). Oleh karena itu, beberapa aspek lainnya seperti bahaya geoteknik (zona likuifaksi, penurunan dan stabilitas tanah dan lereng), bahaya jatuh, bahaya non-struktural dan bahan berbahaya/fasilitas umum. Bentuk lengkap dari metode penilaian ini berkaitan dengan aspek umum dan teknis bangunan. Pengisian formulir Kondisi Bangunan (Umum, Struktur dan Geoteknik) akan mendapatkan poin kumulatif untuk kategori berikut: 0-30 termasuk kerusakan ringan, 30-70 adalah kerusakan sedang dan untuk nilai 70-100 adalah kategori rusak parah.

Langkah-langkah dan prosedurnya pengambilan data dan proses analisis dari bangunan sederhana dan metode perbaikan adalah sebagai berikut :

1) Tahap Persiapan

Bahan dan peralatan yang digunakan antara lain : ATK, GPS/HP dengan GPS, meteran. Data bangunan yang rusak diperoleh dari dinas terkait seperti Dinas PU dan Penataan Ruang, Dinas Perumahan dan Pemukiman, Dinas Pendidikan dan Dinas Kesehatan.

2) Tahap Pengambilan Data lapangan

Data lapangan yang diambil adalah : Nama bangunan, lokasi bangunan, ukuran dan geometri bangunan, dokumentasi kerusakan tiap elemen bangunan, kondisi lingkungan sekitar bangunan dan data lainnya.

3) Tahap Analisis dan Pembahasan Analisis dilakukan terhadap data primer dan data sekunder hasil asesmen lapangan. Berikutnya data lapangan diolah sesuai masing-masing form, baik bangunan sederhana maupun bertingkat. Pembahasan dilakukan setelah dilakukan analisis dan kajian yang relevan.

4) Tahap Kesimpulan dan Saran

Kesimpulan merupakan rangkuman dan ringkasan hasil pembahasan, saran dan rekomendasi akan diberikan terhadap kondisi masing-masing bangunan yang diasesmen kepada pemda dan dinas terkait 
REKOnSTRUKSI TADULAKO: Civil Engineering Journal on Research and Development, Vol. 3(1), March 2022

\section{Hasil dan Pembahasana}

Berdasarkan survey pendahuluan diperoleh data bangunan seperti pada Tabel 2, Gambar 1 dan Gambar 2. Keenam (6) bangunan tersebut dipilih berdasarkan tingkat kepentingan bangunan serta tingkat kerusakan yang dilihat pada saat survey pendahuluan.

Tabel 3. merupakan hasil asesmen dari metode Ditjen Cipta Karya Kementerian PUPR untuk keenam bangunan tersebut diatas. Adapun hasil uraian dari Tabel 3 atas disajikan pada Tabel 4, sebagai contoh diambil hasil asesmen untuk Gedung Walikota Palu. Hasil asesmen tehadap ke 6 (enam) bangunan dengan menggunakan form dari World Bank seperti pada Tabel 5.
Tabel 2. Nama dan alamat bangunan yang diasesmen

\begin{tabular}{cll}
\hline No & \multicolumn{1}{c}{ Nama Bangunan } & \multicolumn{1}{c}{ Alamat } \\
\hline 1 & Kantor Wali Kota Palu & Jl. Balai Kota, Palu \\
\hline 2 & Kantor DPRD Kota Palu & Jl. Moh. Hatta, Palu \\
\hline 3 & Kantor Bupati Donggala & Jl. Jati, Gn. Bale, Donggala \\
\hline 4 & Kantor DPRD Donggala & Jl. Jati, Gn. Bale, Donggala \\
\hline 5 & Kantor DPRD Parigi & $\begin{array}{l}\text { Komplek Perkantoran, } \\
\text { Parigi }\end{array}$ \\
\hline 6 & Moutong & Jl. Sis Aljufri, Parigi \\
\hline
\end{tabular}

Adapun hasil uraian dari Tabel 5 disajikan pada Tabel 6, sebagai contoh diambil hasil asesmen untuk Gedung Walikota Palu

Tabel 3. Hasil asesmen tingkat kerusakan bangunan sesuai form PUPR

\begin{tabular}{llccc}
\hline \multirow{2}{*}{ No } & \multicolumn{1}{c}{ Nama Bangunan } & \begin{tabular}{c} 
Kategori Kerusakan \\
\cline { 3 - 5 }
\end{tabular} & $\begin{array}{c}\text { Rusak } \\
\text { Redangan }\end{array}$ & $\begin{array}{c}\text { Rusak } \\
\text { Berat }\end{array}$ \\
\hline 1 & Kantor Wali Kota Palu & $\mathrm{V}$ & \\
\hline 2 & Kantor DPRD Kota Palu & $\mathrm{V}$ & \\
\hline 3 & Kantor Bupati Donggala & $\mathrm{V}$ & \\
\hline 4 & Kantor DPRD Donggala & $\mathrm{V}$ & \\
\hline 5 & Kantor DPRD Parigi Moutong & & \\
\hline 6 & Gedung RSUD Anuntaloko Parigi & $\mathrm{V}$ & \\
\hline
\end{tabular}

Tabel 4. Hasil asesmen Gedung Kantor Walikota Palu dengan form dari Ditjen Puslitbangkim PUPR

\begin{tabular}{|c|c|c|c|c|c|c|c|c|}
\hline $\mathbf{I}$ & \multicolumn{4}{|l|}{ NAMA BANGUNAN : } & \multicolumn{3}{|c|}{ TGL PEMERIKSAAN } & $\begin{array}{c}\text { TINGKAT } \\
\text { KERUSAKAN }\end{array}$ \\
\hline & \multicolumn{4}{|c|}{ GEDUNG KANTOR WALI KOTA PALU } & \multicolumn{3}{|c|}{6 - Mei - 2021} & $\begin{array}{c}\text { RUSAK } \\
\text { SEDANG }\end{array}$ \\
\hline 1 & ALAMAT & \multicolumn{6}{|c|}{ Jalan Balai Kota Palu } & \\
\hline 2 & PEMILIK BANGUNAN & \multicolumn{6}{|c|}{ Pemda Kota Palu } & \\
\hline 3 & FUNGSI BANGUNAN & \multicolumn{6}{|c|}{ Kantor } & \\
\hline 4 & JENIS STRUKTUR & \multicolumn{6}{|c|}{ Portal Beton Bertulang } & \\
\hline 5 & JUMLAH LANTAI BANGUNAN & \multicolumn{6}{|c|}{2 (Dua) } & \\
\hline 6 & PERKIRAAN LUAS BANGUNAN & \multicolumn{4}{|c|}{$2.125 \mathrm{~m}^{2}$} & & & \\
\hline & TINGKAT KERUSAKAN & \multicolumn{2}{|c|}{ RINGAN } & \multicolumn{2}{|c|}{ SEDANG } & \multicolumn{2}{|c|}{ BERAT } & CATATAN \\
\hline II & \multicolumn{7}{|c|}{ KERUSAKAN BAGIAN LUAR BANGUNAN } & \\
\hline 1 & Penurunan Lantai Bangunan & $\sqrt{ }$ & \multirow{4}{*}{$\begin{array}{l}<0.2 \mathrm{~m} \\
<1 \circ \\
<10 \%\end{array}$} & & \multirow{2}{*}{$\begin{array}{l}0.2-1 \mathrm{~m} \\
1-2 \circ\end{array}$} & & \multirow{2}{*}{$>1 \mathrm{~m}$} & \\
\hline 2 & Kemiringan Bangunan & & & $\sqrt{ }$ & & & & \\
\hline 3 & Jumlah Kolom Rusak & & & & $10-20 \%$ & $\sqrt{ }$ & $>20 \%$ & \\
\hline 4 & Jumlah Dinding Rusak & & & $\sqrt{ }$ & $10-20 \%$ & & $>20 \%$ & \\
\hline 5 & Jumlah Balok Rusak & & $<10 \%$ & & $10-20 \%$ & $\sqrt{ }$ & $>20 \%$ & \\
\hline 6 & Jumlah Atap Rusak & \multirow[t]{3}{*}{$\sqrt{ }$} & $<10 \%$ & & $10-20 \%$ & & $>20 \%$ & \\
\hline 7 & Jatuhan Dinding/ Jendela & & $<1 \%$ & $\sqrt{ }$ & $1-10 \%$ & & $>10 \%$ & \\
\hline 8 & Kerusakan Tangga, dll & & $<1 \%$ & $\sqrt{ }$ & $1-10 \%$ & & $>10 \%$ & \\
\hline III & \multicolumn{7}{|c|}{ KERUSAKAN BAGIAN DALAM BANGUNAN } & \\
\hline 1 & Jumlah Kolom Rusak & $\sqrt{ }$ & $<10 \%$ & & $10-20 \%$ & & $>20 \%$ & \\
\hline 2 & Jumlah Dinding Rusak & & $<10 \%$ & $\sqrt{ }$ & $10-20 \%$ & & $>20 \%$ & \\
\hline 3 & Jumlah Balok Rusak & & $<10 \%$ & $\sqrt{ }$ & $10-20 \%$ & & $>20 \%$ & \\
\hline 4 & Jumlah Plafon Rusak & & $<10 \%$ & $\sqrt{ }$ & $10-20 \%$ & & $>20 \%$ & \\
\hline 5 & Jumlah Jatuhan Partisi, dll & $\sqrt{ }$ & $<10 \%$ & & $10-20 \%$ & & $>20 \%$ & \\
\hline 6 & Jumlah instalasi, dll & $\sqrt{ }$ & $<10 \%$ & & $10-20 \%$ & & $>20 \%$ & \\
\hline
\end{tabular}


REKOnSTRUKSI TADULAKO: Civil Engineering Journal on Research and Development, Vol. 3(1), March 2022

Tabel 5. Hasil asesmen tingkat kerusakan bangunan berdasarkan Metode World Bank

\begin{tabular}{|c|c|c|c|c|c|}
\hline \multirow{2}{*}{ No } & \multirow{2}{*}{ Nama Bangunan } & \multirow{2}{*}{$\begin{array}{l}\text { Nilai } \\
\text { Score }\end{array}$} & \multicolumn{3}{|c|}{ Kategori Kerusakan } \\
\hline & & & Rusak Ringan & Rusak Sedang & Rusak Berat \\
\hline 1 & Kantor Wali Kota Palu & 41,7 & & $\sqrt{ }$ & \\
\hline 2 & Kantor DPRD Kota Palu & 10,5 & $\sqrt{ }$ & & \\
\hline 3 & Kantor Bupati Donggala & 20,1 & $\sqrt{ }$ & & \\
\hline 4 & Kantor DPRD Donggala & 20,1 & $\sqrt{ }$ & & \\
\hline 5 & Kantor DPRD Parigi Moutong & 52,1 & & $\sqrt{ }$ & \\
\hline 6 & Gedung RSUD Anuntaloko Parigi & 27,7 & $\sqrt{ }$ & & \\
\hline
\end{tabular}

Tabel 6. Hasil asesmen bangunan gedung Kantor Wali Kota Palu

\begin{tabular}{|c|c|c|c|c|c|c|c|c|c|c|c|c|c|c|}
\hline Notasi & G1 & St1 & St2 & St4 & St6 & St8 & St9 & St10 & NSt1 & NSt2 & NSt3 & Geo1 & Geo2 & Geo3 \\
\hline Bobot Nilai & 0,09 & 0,11 & 0,11 & 0,08 & 0,08 & 0,08 & 0,08 & 0,08 & 0,04 & 0,04 & 0,04 & 0,07 & 0,05 & 0,05 \\
\hline Nilai kuisioner & 30 & 0 & 30 & 30 & 70 & 100 & 100 & 100 & 30 & 30 & 0 & 0 & 100 & 0 \\
\hline Nilai akhir & 2,7 & 0 & 3 & 1,8 & 5,7 & 7 & 6 & 6 & 1,8 & 1,8 & 0 & 0 & 6 & 0 \\
\hline Skor & \multicolumn{14}{|c|}{ Score : 41,7 (Rusak Sedang) } \\
\hline
\end{tabular}

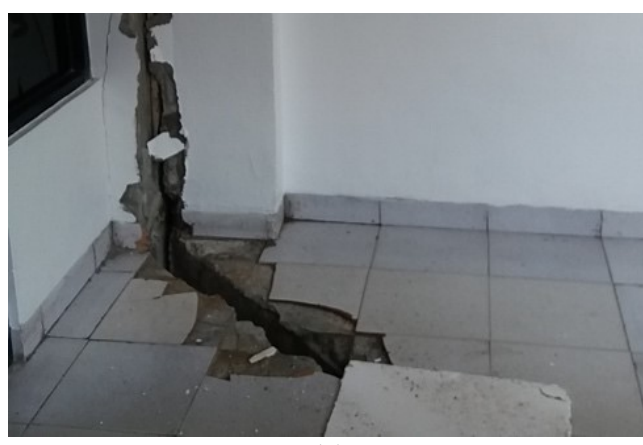

(a)

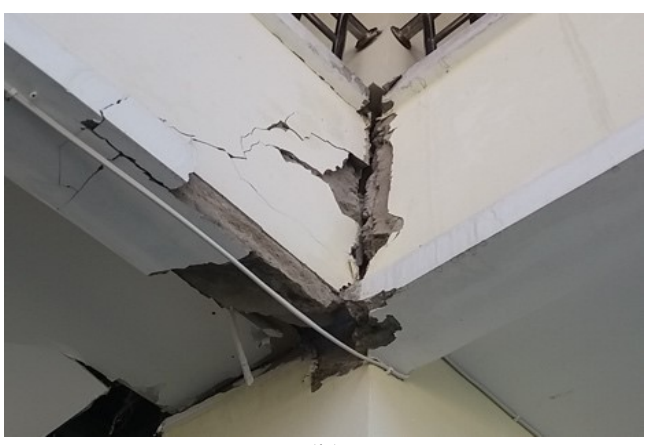

(b)

Gambar 1. Bangunan dengan kategori Rusak Sedang Kantor Wali Kota Palu, (b) Kantor DPRD Kabupaten Parigi Moutong

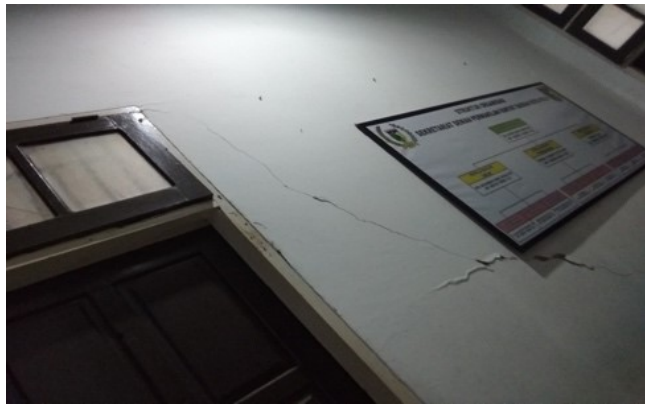

(a)

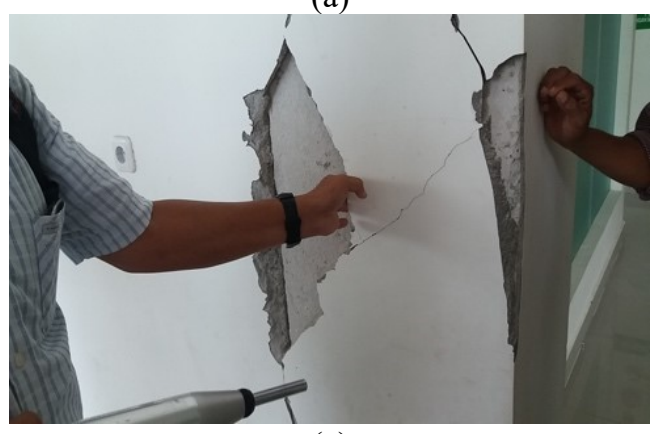

(c)

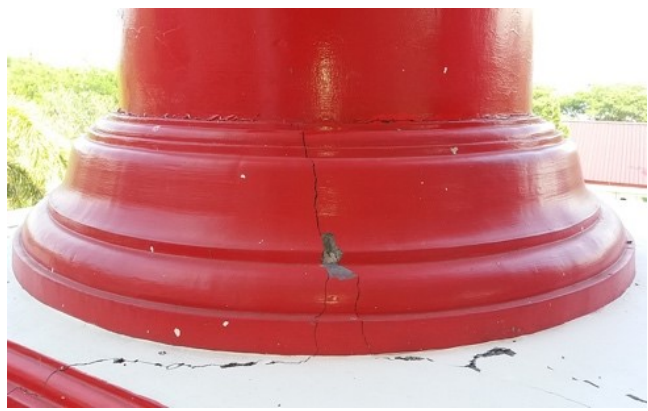

(b)

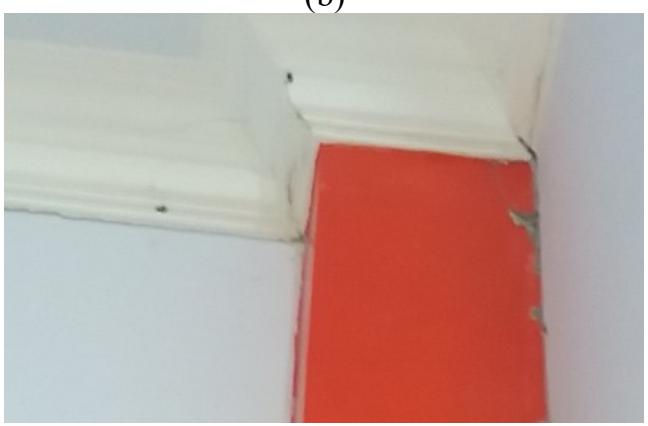

(d)

Gambar 2. Bangunan dengan kategori Rusak Ringan: (a). Kantor DPRD Kota Palu, (b) Kantor Bupati Donggala, (c) Kantor DPRD Kab. Donggala, (d) RSUD Anuntaloko Parigi) 
Jenis kerusakan elemen struktural maupun non struktural pada keenam bangunan tersebut dapat diuraikan sebagai berikut :

1) Kerusakan elemen-elemen strutural pasca gempa 28

September 2018 berupa :

a) Rekahan atau retak terbuka pada sudut-sudut massa bangunan gedung Kantor Wali Kota Palu (Gambar 1a).

b) Retakan pada ujung-ujung atas kolom lantai 1 (satu) pada bangunan gedung Kantor DPRD Kabupaten Parigi Moutong (Gambar 1b).

c) Retakan struktur lainnya berupa retak ringan pada ujung bawah kolom seperti pada bangunan gedung Kantor Bupati dan DPRD Kabupaten Donggala (Gambar 2b dan Gambar 2c).

d) Pergeseran pada area dilatasi antar kolom seperti pada bangunan RSUD Anuntaloko Parigi (Gambar 2d)

2) Kerusakan elemen-elemen nonstruktural

Kerusakan non struktural pasca gempa 28 September 2018 pada bangunan yang diasesmen berupa kerusakan tipikal berupa :

a) Retakan kecil hingga rekahan pada dinding partisi

b) Runtukan penutup hingga rangka plafond khususnya yang menggunakan rangka plafond baja ringan (kasus di bangunan Kantor DPRD Kabupaten Parigi Moutong.

c) Terkupasnya beberapa lapisan penutup lantai.

d) Retakan pada kolom ornament yang didalamnya dipasang pipa air hujan (kasus pada bangunan RSUD Anuntaloko Parigi).

e) Runtuhan kuda-kuda pasangan batu bata (kasus pada Kantor DPRD Kabupaten Parigi Moutong dan kantor Bupati Kabupaten Donggala).

f) Retakan dinding pada area: sudut kusen, bawah kusen, pertemuan dinding-kolom praktis.

g) Terkupasnya plesteran kolom.

h) Rekahan pada talud pasangan pondasi batu kali (kasus pada kantor Bupati Kabupaten Donggala).

i) Lapuknya penutup plafond seperti pada kantor DPRD Kota Palu (Gambar 2a).

Berdasarkan data kategori kerusakan serta jenis dan tipe kerusakan dapat diberikan metode perbaikan pada tahapan rehab rekon sebagai berikut :

1) Perbaikan elemen struktural meliputi :

a) Untuk rekahan pada plat lantai gedung kantor DPRD Kota Palu sebaiknya dilakukan antar massa bangunan. Bangunan bentuk denah angka 8 (delapan) sebaiknya dibuat dilatasi dengan jarak celah $10 \mathrm{~cm}$. pada area pertemuan antar massa bangunan. Penutup celah bisa digunakan bahan karet (elastomer).

b) Untuk retakan cukup besar pada joint balok-kolom pada bangunan kantor DPRD Parigi Moutong sebaiknya dilakukan grouting bahan semen grout sejenis produksi SIKA. Sebelum dibobok semua balok harus disokong dengan shoring baja profil. Setelah bahan grouting berumur sekitar 2 (dua) minggu barulah shoring nya dilepas kembali. c) Untuk kerusakan struktur dengan kategori ringan berupa retakan kecil, bisa dilakukan injeksi bahan anti susut dari produk sejenis SIKA. Bahan dan peralatan harus sesuai persyaratan untuk pekerjaan injeksi untuk pekerjaan perbaikan dan perkuatan struktur.

d) Perbedaan deformasi permanen pada kolom berdekatan (area dilitasi antar bangunan), seperti kasus gedung Rawat Inap RSUD Anuntaloko Parigi, perbaikan dilakukan dengan tambahan plesteran pada kolom sehingga tidak terlihat lagi perbedaan posisi kolom. Hal ini untuk mengembalikan segi estetika bangunannya.

2) Perbaikan elemen nonstruktural meliputi:

a) Retakan kecil hingga rekahan pada dinding dilakukan perbaikan berupa pengupasan plesteran, penjahitan atau penembahan tulangan dan kawat ram dan kemudian diplester kembali.

b) Untuk runtuhan pada kuda-kuda batu bata dilakukan perkuatan kolom dan ring balok keliling sehingga jika terjadi gempa tidak akan runtuh lagi.

c) Plafond dengan rangka baja ringan sebaiknya diganti dengan rangka kayu. Untuk penutup plafond gipsun juga diganti dengan triplek, lembersering, calsiboard atau bahan lain yang tidak mudah runtuh saat terjadi gempa. Penutup plafond yang lapuk akibat hujan juga diganti, sebelum diganti kebocoran atap harus diperbaiki.

- Penutup lantai yang lepas langsung diganti.

- Kolom ornament dari pasangan batako untuk menutupi saluran pipa air hujan diganti dengan ornament baja siku dengan penutup calsiboard atau bahan laian yang tahan cuaca.

- Talud pasangan batu kali yang merekah atau retak terbuka dibongkar dak ditambahkan struktur kolom dan balok slof agar menyatu dan tidak mudah terlepas saat terjadi gempa.

\section{Kesimpulan}

Berdasarkan hasil dan pembahasan maka dapat disampaikan beberapa kesimpulan sebagai berikut :

1) Bangunan yang diasesmen dari ke 3 (tiga) wilayah yaitu : Kota Palu, Kabupaten Donggala dan Parigi Moutong, telah mengalami kerusakan pasca gempa 28 September 2018.

2) Kategori kerusakan dari bangunan yang diperiksa yaitu : 4 (empat) bangunan yang mengalami Rusak Ringan yaitu : bangunan gedung Kantor DPRD Palu, Kantor Bupati dan DPRD Dongggala dan bangunan Rawat Inap RSUD Anuntaloko Parigi. Sedangkan yang Rusak Sedang adalah bangunan Kantor Wali Kota Palu dan Kantor DPRD Parigi Moutong.

3) Hasil kategori kerusakan dengan menggunakan form dari Ditjen Puslitbangkim PUPR dan form dari World Bank (WB) menghasilkan tingkat kategori kerusakann yang sama.

4) Bangunan yang mengalami tingkat kerusakan Rusak Ringan dan Rusak Sedang masih bisa dilakukan perbaikan dan perkuatan sehingga nantinya pasca rehab rekon masih dapat dipergunakan kembali. 
5) Pemilihan metode, bahan dan alat serta teknologi dan personal yang akan melakukan pekerjaan perbaikan dan perkuatan harus dilakukan dengan sebaik-baiknya agar bangunan pasca perbaikan dan perkuatan dapat menahan beban-beban yang bekerja pada saat difungsikan kembali.

\section{Kesimpulan}

[1] C.S. Oliveira, The Influence of Scale on Microzonation and Impact Studies, Netherland: Kluwer Academic Publihshing, 2004.

[2] A. Widiati, "Aplikasi Manajemen Risiko Bencana Alam dalam Penataan Ruang Kabupaten Nabire", Jurnal Sain dan Teknologi Indonesia, vol. 10, no. 1, 2008.

[3] E. Anantasari, M. Daly, P. Glassey, E. Grace, M. Coomer, and R. Wood, "Disaster Risk Reduction in Indonesia, Disaster Risk Reduction", Disaster Risk Reduction, p. 147, 2017.

[4] G. Ananda, T. Ophyandri, and E. Hasymi, "Resilience Measurement of Padang City's Infrastructures Toward Multi-Hazard", Proc. $4^{\text {th }}$ International Conference on Earthquake and Disaster Mitigation, p. 1, 2019.

[5] K,S. Vatsa, "Risk, vulnerability, and asset-based approach to disaster risk management", International Journal of Sociology and Social Policy, vol. 24 no. 10, p.1, 2004.

[6] R. Paulik, "Tsunami Hazard and Built Environment Damage Observations from Palu City after the September 282018 Palu Earthquake and Tsunami", Pure and Applied Geophysics, vol. 176, p. 3305, 2019.

[7] I.M. Watkinson and R. Hall, "Fault Systems of the Eastern Indonesian Triple Junction: Evaluation of Quaternary Activity and Implications for Seismic Hazards". Geological Society, vol. 441, no. 1, p. 71, 2016.

[8] A. Kijko, S.J.P. Retief, and G. Graham "Seismic Hazard Risk Assessment Tulbagh, South Africa: Part II - Assessment of Seismic Risk", Natural Hazard, vol. 30, p. 25, 2003.

[9] Badan Nasional Penanggulangan Bencana, Kerangka Kerja Sendai untuk Pengurangan Risika Bencana, Jakarta: BNPB, 2015T. Andriono and G. Kusuma, Strudi tentang Prosedur Pemeriksaan Ketahan Struktur Rangka Beton Bertulang, Surabaya: Jurusan Teknik Sipil Universitas Petra, 1999.
[10] Y. Afriadi and I. Satyarno, "Perbandingan Spektra Desain Beberapa Kota Besar di Indonesia dalam SNI Gempa 2012 dan SNI Gempa 2012”, Prosiding Konferensi Nasional Teknik Sipil 7 (KoNTekS 7), Univesitas Sebelas Maret Surakarta, p. 1, 2013.

[11] I.K. Sulendra, "Asesment Bangunan Gedung di Universitas Tadulako Palu pasca Gempa 28 September 2018 untuk Pelaksanaan Rehabilitasi dan Rekonstruksi", Rekonstruksi Tadulako: Civil Engineering Journal on Research and Development, vol. 2 , no. 1, p. 47, 2021.

[12] I.K. Sulendra, A. Dolu, I.S. Oktaviana, and T.M. Kamaludin, "Lesson Learned from 28 September 2018 Palu-Donggala Earthquake", Proc. 4th International Conference on Earthquake Engineerung and Disasters Management, p. 1, 2019.

[13] A. Dolu, I.K. Sulendra, J. Hasan, and G.M. Oka, "Kegagalan Struktur Bangunan dan Jembatan Saat Gempa Palu 28 September 2018", Prosiding Konferensi Nasional Teknik Sipil ke-13, vo1. 1, p. 1, 2019.

[14] Tim Pusat Studi Gempa Nasional, Kajian Gempa Palu Provinsi Sulawesi Tengah, Jakarta: Pusat Studi Gempa Nasional (PuSGeN), 2019.

[15] Badan Standar Nasional, Standar Perencanaan Ketahanan Gempa Untuk Struktur Bangunan Gedung SNI-1726-2019, Jakarta: Badan Penelitian dan Pengembangan Pemukiman dan Prasarana Wilayah, Pusat Penelitian dan Pengembangan Teknologi

[16] Direktorat Jenderal Cipta Karya, Form Penilaian Keandalan Struktur Bangunan Gedung rangka Beton dengan Pasangan Dinding, Jakarta: Departemen Pekerjaan Umum, 2008.

[17] Pusat Pengembangan Perumahan dan Pemukiman, Panduan Praktis Pemeriksaan Kerusakan Rumah Tembok akibat Gempa Bumi, Bandung: Kementerian Pekerjaan Umum dan Perumahan Rakyat, 2006.

[18] PUPR, Behavior of Building during Earthquake, Technical Knowledge Sharing, Palu: PUPR-World Bank, 2020.

[19] Badan Nasional Penanggulangan Bencana, Kerangka Kerja Sendai untuk Pengurangan Risika Bencana, Jakarta: BNPB, 2015 